\title{
PARATHYROID ADENOMA WITH MISLEADING PHOSPHATE EXCRETION TESTS
}

\author{
BY \\ H. G. MORGAN, W. K. STEWART, AND J. GRIEVE \\ From the Departments of Pathology, Medicine, and Surgery of the University of St. Andrews, \\ Queen's College, Dundee
}

(RECEIVED FOR PUBLICATION APRIL 10, 1960)

\begin{abstract}
A patient with primary hyperparathyroidism is described in whom, pre-operatively, the renal tubular handling of phosphate was within the limits accepted by recent writers as normal. The tests they advocate were, therefore, shown to be unreliable in this disease. The hypercalcaemia of primary hyperparathyroidism is one type of hypercalcaemia that is apparently not reduced to normal after the administration of an adequate dosage of cortisone. In our patient, such a "cortisone-fast" finding is documented, and was a valuable aid in the decision to operate.
\end{abstract}

In the earlier descriptions of primary hyperparathyroidism most of the patients were suffering from symptomatic bone disease, the osteitis fibrosa cystica of von Recklinghausen (Norris, 1947). To-day most examples of hyperparathyroidism come to light in the investigation of patients with calcification in the urinary tract. In the literature from 1948 to 1954 , of 236 patients with hyperparathyroidism, $178(75 \%)$ had renal tract disorders, chiefly stone or nephrocalcinosis (Albright and Reifenstein, 1948; Black, 1953 ; Hellström, 1954), and by 1955 Black states that only about $5 \%$ of patients with hyperparathyroidism have "osseous complications." On the other hand, of several hundred patients with urinary calculi examined in that era, just under $7 \%$ were found to have hyperparathyroidism (Albright and Reifenstein, 1948; Beard and Goodyear, 1950).

In such patients the diagnosis hinges on the finding or exclusion of the biochemical criteria of hyperparathyroidism. Of these, hypercalcaemia is a sine qua non, although it is not pathognomonic. If it be accompanied by a low fasting plasmainorganic-phosphorus level then hyperparathyroidism is likely, but unfortunately parathyroid overactivity cannot be excluded if the plasma phosphorus is normal, for Goldman, Gordan, and Chambers (1957) have shown that a high calcium and normal phosphorus can occur in hyperparathyroidism even in the absence of renal failure.

In the continued lack of a diagnostic hormone assay, various additional chemical investigations have recently been proposed as aids to the diagnosis, especially of the milder forms of the disease. These tests have mainly been focused on phosphaturia.

Change in inorganic-phosphate reabsorption by the renal tubules was suggested by Crawford, Osborne, Talbot, Terry, and Morrill (1950) as an index of parathyroid function, and a striking? increase in renal phosphate reabsorption following parathyroidectomy in man was described by Sirota (1953). Other workers (Schaaf and Kyle, 1954 ; Nordin and Fraser, 1956; Bogdonoff, Woods, White, and Engel, 1956; Goldman et al., 1957 ; Kyle, Schaaf, and Canary, 1958) have now described a variety of tests for renal handling of phosphate, with the suggestion that these are of real significance in the positive identification or exclusion of primary hyperparathyroidism.

In the patient to be described, with a proved parathyroid adenoma, the pre-operative renal handling of phosphate, as measured by several of the published tests (Bogdonoff et al., 1956; Goldman et al., 1957 ; Kyle et al., 1958 ; Nordin, 1958), indicated normal parathyroid function. Fortunately for the patient the implications of those results were not accepted as a contraindication to surgical exploration.

\section{Case Report}

A 57-year-old widow was admitted in January, 1958, for investigation of hypercalcaemia. In October, 1956, and again in March, 1957, she had brief episodes of left renal colic. Other complaints at these times were long-standing backache, constipation, dysphagia, and dyspepsia, and recently frequency of micturition, with nocturia. Urine analysis was 
Cortisone mg.per day

$$
\left.\begin{array}{c}
150 \\
0
\end{array}\right]
$$
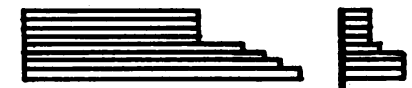

Phosphate excretion index

Clearance of Phosphate ml. per min.

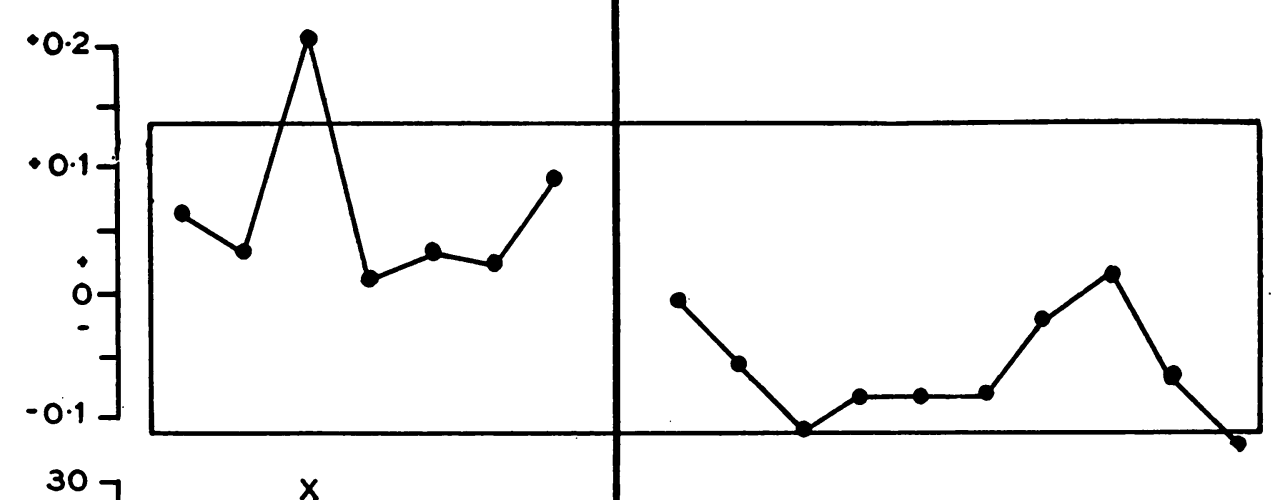

Tubular re-absorption $90-$ of Phosphate (percentage)<smiles>OCC(O)C([18OH])C([18OH])CO</smiles>
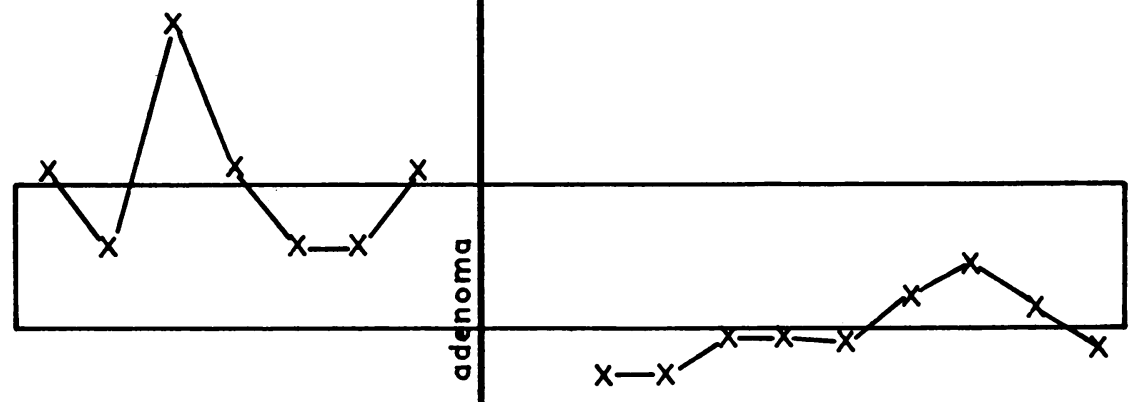

Tubular re-absorption of Phosphate 3.5mg.P.per 100 $\mathrm{mft}^{3}$. glomerular filtrate
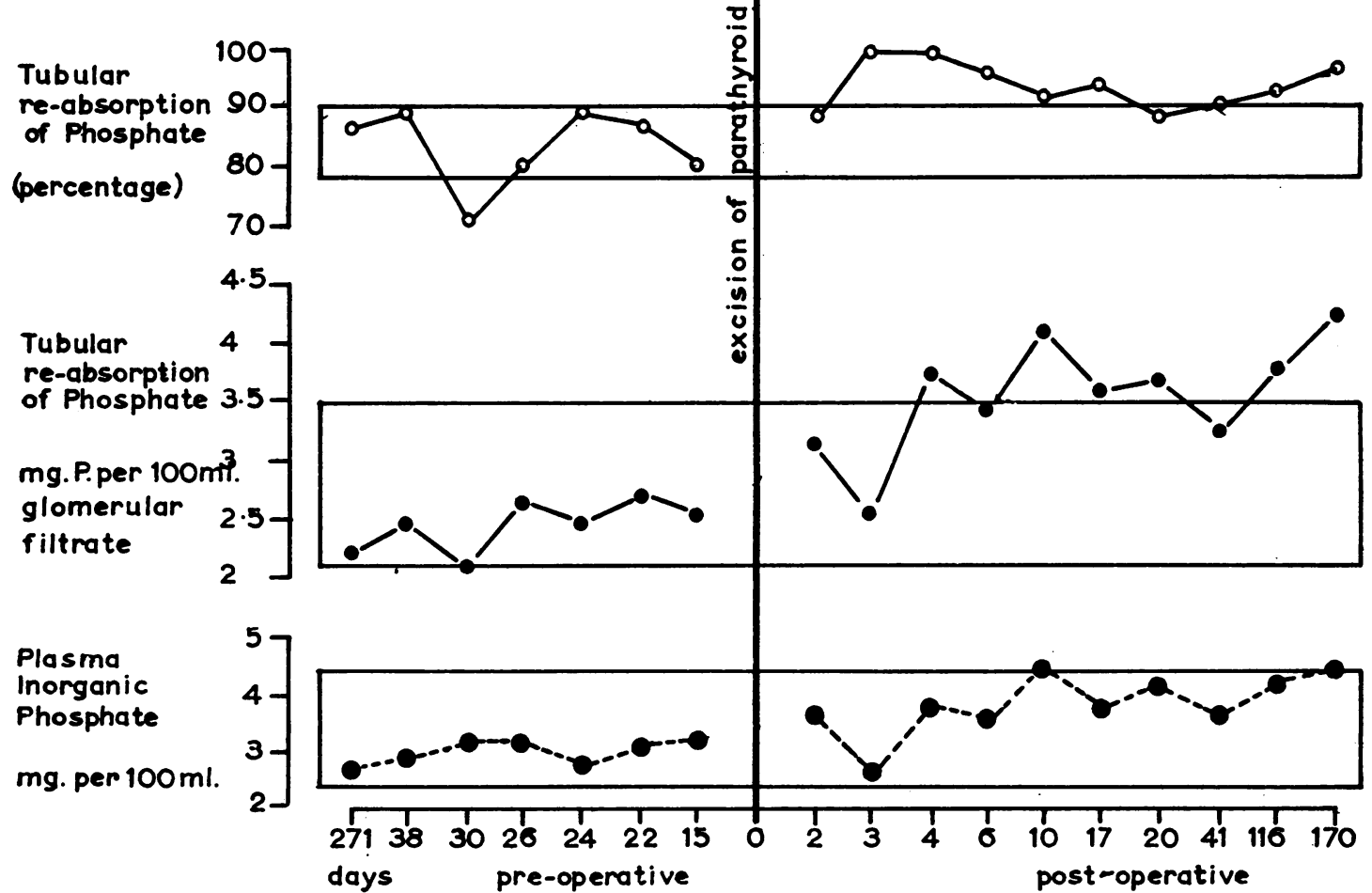

Fig. 1.-Results of renal tubular handling of phosphate expressed in four ways. These are within normal limiıs (within rectangles) before parathyroidectomy, except for one result. Note that this time scale is not linear. 
always negative, no renal tract abnormality was shown by radiography, and she could concentrate to S.G. 1027. In 1957, plasma calcium values ranged between 11.8 and $13.0 \mathrm{mg}$. per $100 \mathrm{ml}$., but the corresponding plasma inorganic phosphorus values (probably not fasting) were within the normal range for this hospital, between 2.4 and $2.9 \mathrm{mg}$. per $100 \mathrm{ml}$. On a low calcium diet, successive 24-hour urinary calcium values were 350,416 , and $520 \mathrm{mg}$.

Past Health.- She had a severe Plummer-Vinson syndrome about 1938. A gastric ulcer of the lesser curvature was shown in 1948 . For 12 months in 1951 and 1952 , from 50,000 to 150,000 international units of ergocalciferol was given daily for lupus vulgaris of the cheek.

Present Admission.-In January, 1958, she looked plump and fit, but had tenderness of the left loin and several patches of active lupus vulgaris on one cheek. Band calcification was seen in both corneae.

The chemical findings included persistent hypercalcaemia and normal plasma phosphorus levels. The blood urea and plasma electrolytes were normal and there was no proteinuria. Endogenous creatinine clearances ranged between 89 and $94 \mathrm{ml}$. per minute. The tubular reabsorption of phosphate (T.R.P.) figures were also within the normal limits of published criteria (vide supra) (Figs. 1 and 2), the 24-hour urinary output of phosphorus being throughout in the range $714-850 \mathrm{mg}$., i.e., the patient was not on a low phosphate intake. Blood was always withdrawn at the same time each morning, with the patient in the fasting state to avoid post-prandial and diurnal variations in blood levels (Stanbury, 1958).

An exhaustive search was made for neoplasm. Oesophagoscopy showed a simple "web" stricture ; dilatation of this relieved dysphagia. A chest radiograph, a barium meal, and tests for faecal occult blood were negative. Marrow from the sternum and ilium showed no infiltrate; she had a mild hypochromic microcytic anaemia (Hb $10.9 \mathrm{~g}$. per $100 \mathrm{ml}$.). An extensive, but negative, survey was made of the bones, particularly for the subperiosteal bone resorption and other changes of hyperparathyroidism (Pugh, 1951).

Hyperparathyroidism seemed the probable cause of the hypercalcaemia, but because no abnormality in phosphate metabolism could be demonstrated, we undertook the cortisone test advocated by Dent (1956). Oral cortisone acetate was given continuously for 18 days, $150 \mathrm{mg}$. daily for the first 10 days, after which the dose was tapered off over eight days. As no significant change occurred in the serum calcium level (Fig. 1), we recommended operation.

Operation.-On February 15, 1958, a 2.25 g. right upper parathyroid adenoma was removed, microscopically of chief-cell type.

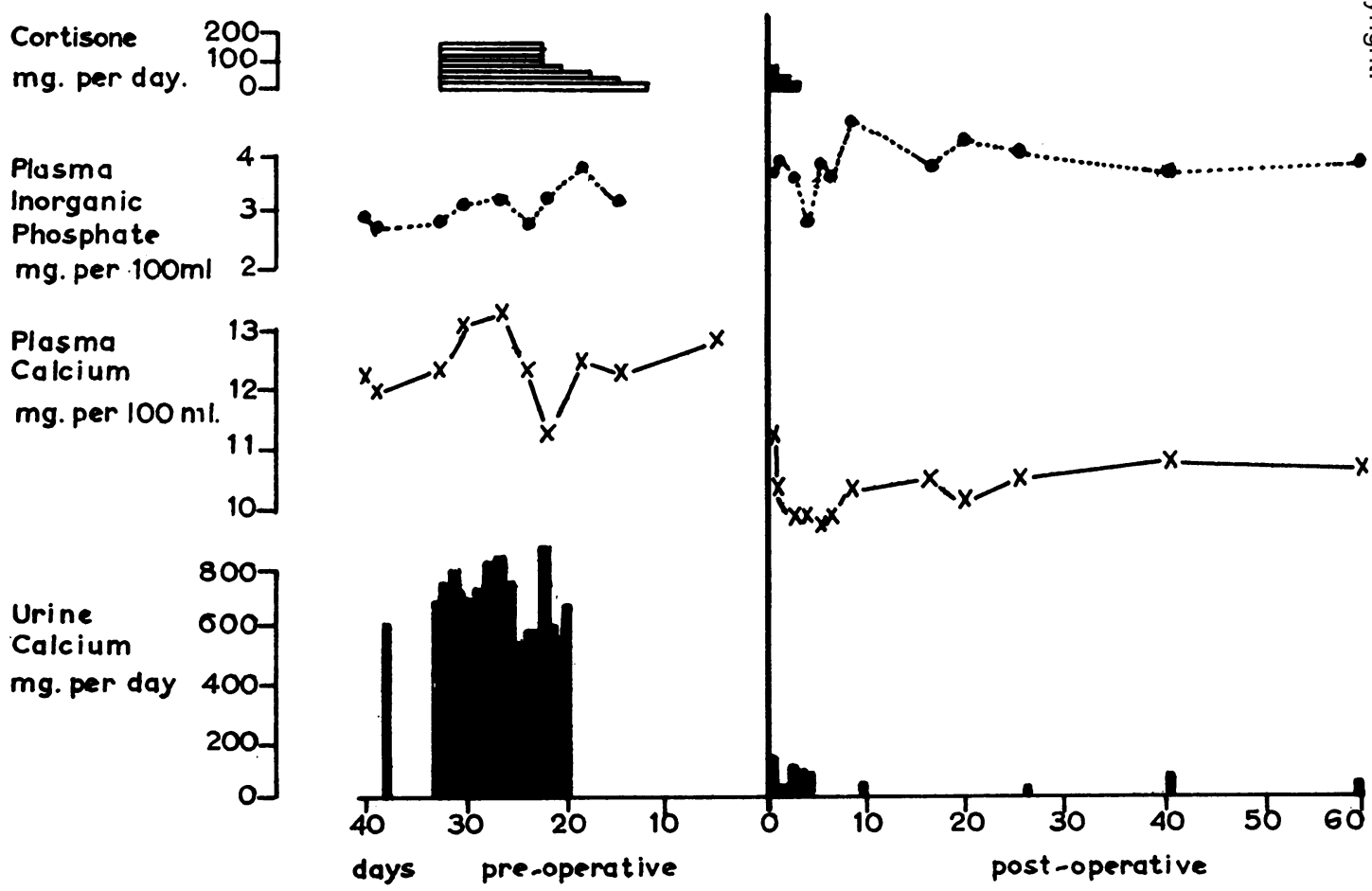

FIG. 2.-Results of the "cortisone" test and of excision of the parathyroid adenoma. Cortisone did not affect significantly the level either of the plasma or of the urinary calcium. 
Progress.-Twenty-four hours later, the plasma calcium had fallen to $10.1 \mathrm{mg}$. per $100 \mathrm{ml}$. and thereafter fell further to $9.4 \mathrm{mg}$. per $100 \mathrm{ml}$., but soon stabilized (Fig. 1). Tetany did not occur. The plasma phosphorus values rose equally rapidly, to high normal levels; there were corresponding changes in the various calculated indices of renal tubular handling of inorganic phosphate. Indeed, some of these indices remained for months at levels indicative of hypoparathyroidism (Fig. 2), thus confirming the ablation of a functional tumour. The 24-hour urinary output of calcium and of phosphorus also fell at once post-operatively; the phosphorus output attained previous levels after about six weeks, and the urinary calcium remained at under $100 \mathrm{mg}$. per 24 hours for six months.

Symptomatically the patient noticed an early improvement in her sense of general well-being and also complete freedom from her backache, left flank pain, and chronic dyspepsia ; she gained $9 \mathrm{lb}$. in eight weeks. This sense of well-being has been maintained. Six months later the corneal calcification had lessened but left some fine scarring.

\section{Comment}

Other than hyperparathyroidism, there are many conditions associated with hypercalcaemia (Thomas, Connor, and Morgan, 1958). These include myeloma and a wide variety of other malignant diseases, sarcoidosis, the milk-alkali syndrome, hypervitaminosis $\mathrm{D}$, the idiopathic hypercalcaemias of infancy, hyperthyroidism (Koenig, Scholz, and Salassa, 1957), adrenal insufficiency (Leeksma, De Graeff, and De Cock, 1957), and extensive skeletal immobilization even of normal people, but especially of those with Paget's disease (Stein, Stein, and Beller, 1955). Thorough physical examination and appropriate investigations will identify some of these states, though neoplastic involvement of bone may be present without radiological evidence (Plimpton and Gellhorn, 1956). Hypercalcaemia itself may cause indeterminate symptoms indistinguishable from those of hyperparathyroidism, such as anorexia and constipation (Albright and Reifenstein, 1948), and this simulation is even more marked in the rare case where hypercalcaemia is accompanied by hypophosphataemia (Thomas et al., 1959). Hypercalciuria is of no differential value, as it occurs with any rise in plasma calcium and also is now known to be common among patients with renal calculi who have neither hypercalcaemia nor hyperparathyroidism (Pyrah, 1958); vitamin $D$ in high dosage too can cause hypercalciuria without hypercalcaemia (Howard, 1953).

The importance and difficulty of deciding the cause of hypercalcaemia are shown in the efforts to evolve more informative tests of the action of the parathyroids on the kidney, but the pity is that undue reliance on these diagnostic refinements has already led to useless surgical explorations both published (McGeown and Montgomery, 1956 ; Beare and Knudsen, 1956) and unpublished. There was a failure to appreciate the influence of such factors as diet, diurnal variation, the absolute level of plasma phosphorus (Stanbury, 1958) and depressed renal function (Goldman and Bassett, 1954) on these newer measurements of hyperphosphaturia, especially on the phosphate clearance and the percentage tubular reabsorption of phosphate. Attempts to overcome the effects of diverse plasma phosphorus levels were made in the phosphate excretion index of Nordin and Fraser (1956), and in the absolute expression " $\mathrm{mg}$. of phosphate reabsorbed per $100 \mathrm{ml}$. glomerular filtrate" (Thomas et al., 1958).

In reviewing the results of such tests on 118 patients with renal calculi, McGeown (1957) has now reported seven examples of tests falsely indicating hyperparathyroidism in patients with persistently normal serum and urinary calcium values. More recently, "false positive" results with a low percentage tubular reabsorption of phosphate have also been shown in seven hypercalcaemic patients without primary hyperparathyroidism (Thomas et al., 1958).

In our patient renal function was normal, as judged by endogenous creatinine clearance and concentration tests, the pre-operative renal phosphate handling was within normal limits by published standards (Fig. 2) and yet a functioning parathyroid adenoma was present. Removal of this adenoma was rapidly followed by significant enhancement of tubular phosphate reabsorption, as shown by a reduction in urinary phosphorus excretion and an increase in plasma phosphorus. It was only in retrospect, by comparison of the post-operative and the apparently normal preoperative values, that the degree of phosphaturia before the operation could be recognized as being relatively high. Thus this patient might have been denied the benefits of operation had the finding of "normal" phosphate handling been accepted as excluding hyperparathyroidism (Goldman et al., 1957 ; Kyle et al., 1958 ; Nordin, 1958).

Our patient is not unique in this respect, since McGeown (1957) has already mentioned three patients with proved hyperparathyroid states in whom the plasma phosphorus levels in the blood were normal and the percentage of phosphate reabsorption by the tubules was also normal. 
The hypercalcaemia of hyperparathyroidism is said by Dent (1956) and Connor, Hopkins, Thomas, Carey, and Howard (1956) to show a specific resistance to lowering by the administration of cortisone, and although this has not yet been widely confirmed (Thomas et al., 1959) no exceptions are known to us. It was mainly on the findings with this test, taken with the clinical background, that we were encouraged to make a firm diagnosis of hyperparathyroidism. Apart from the benefit to the patient, this result encourages further evaluation of the response to cortisone in the analytical diagnosis of hypercalcaemia.

We thank Professor A. C. Lendrum, Professor I. G. W. Hill, and Dr. K. G. Lowe for continuous encouragement, Miss M. R. Haslock, B.Sc., for the many technical estimations, Dr. A. A. Douglas for the slit lamp observations, and Mr. J. Mowat for the oesophagoscopy.

One author (W. K.S.) is in receipt of a grant from the Scottish Hospital Endowments Research Trust, to whom acknowledgment is made.

\section{REFERENCES}

Albright, F., and Reifenstein, E. C., Jr. (1948). The Parathyroid Glands and Metabolic Bone Disease. Baillière, Tindall \& Cox, Baltimore.

Beard, D. E., and Goodyear, W. E. (1950). J. Urol. (Baltimore), 64, 638.

Beare, R. L. B., and Knudsen, E. T. (1956). Brit. med. J., 2, 1526.
Black, B. M. (1953). Primary Hyperparathyroidism. Ed. W. O. Thompson. Illinois.

(1955). A.M.A. Arch. Surg., 71, 485.

Bogdonoff, M. D., Woods, A. H., White, J. E., and Engel, F. L. (1956). Amer. J. Med., $21,583$.

Connor, T. B., Hopkins, T. R., Thomas, W. C., Carey, R. A., and Howard, J. E. (1956). J. clin. Endocr., 16, 945.

Crawford, J. D., Osborne, M. M., Jr., Talbot, N. B., Terry, M. L., and Morrill, M. F. (1950). J. clin. Invest., 29, 1448.

Dent, C. E. (1956). Brit. med. J., 1, 230.

Goldman, L., Gordan, G. S., and Chambers, E. L., Jr. (1957). Ann. Surg., 146, 407.

Goldman, R., and Bassett, S. H. (1954). J. clin. Invest., 33, 1623.

Hellström, J. (1954). Acta endocr. (Kbh.), 16, 30.

Howard, J. E. (1953). Trans. 5th Conf. Metabolic Interrelations. Josiah Macy, Jr., Foundation.

- Carey, R. A., Rubin, P. S., and Levine, M. D. (1949). Trans. Ass. Amer. Phycns, 62, 264.

Koenig, M. P., Scholz, D. A., and Salassa, R. M. (1957). Minn. Med., 40, 782.

Kyle, L. H., Schaaf, M., and Canary, J. J. (1958). Amer. J. Med., 24,240 .

Leeksma, C. H. W., De Graeff, J., and De Cock, J. (1957). Acta med. scand., 156, 455.

McGeown, M. G. (1957). Clin. Sci., 16, 297.

and Montgomery, D. A. D. (1956). Brit. med. J., 1, 86.

Nordin, B. E. C. (1958). Advanc. intern. Med., 8, 81.

- and Fraser, R. (1956). In Ciba Foundation Symposium on Bone Structure and Metabolism. Ed. Wolstenholme, G. E. W., and O'Connor, C. M., p. 222. Churchill, London.

Norris, E. H. (1947). Int. Abstr. Surg., 84, 1.

Plimpton, C. H., and Gellhorn, A. (1956). Amer. J. Med., 21, 750.

Pugh, D. G. (1951). Amer. J. Roentgenol., 66, 577.

Pyrah, L. N. (1958). Proc. roy. Soc. Med., 51, 183.

Schaaf, M., and Kyle, L. H. (1954). Amer. J. med. Sci., 228, 262.

Sirota, J. H. (1953). Fed. Proc., 12, 133.

Stanbury, S. W. (1958). Advanc. intern. Med., 9, 231.

Stein, I., Stein, R. O., and Beller, M. L. (1955). Living Bone in Health and Disease. Pitman Medical Publishing Co., London.

Thomas, W. C., Connor, T. B., and Morgan, H. G. (1958). J. Lab. clin. Med., 52, 11. 